\title{
Two-Dimensional MXenes as Catalysts for Electrochemical Hydrogen Evolution: A
} Computational Screening Study

\author{
Pandey, Mohnish; Thygesen, Kristian Sommer
}

Published in:

Journal of Physical Chemistry C

Link to article, DOI:

10.1021/acs.jpcc.7b05270

Publication date:

2017

Document Version

Peer reviewed version

Link back to DTU Orbit

Citation (APA):

Pandey, M., \& Thygesen, K. S. (2017). Two-Dimensional MXenes as Catalysts for Electrochemical Hydrogen Evolution: A Computational Screening Study. Journal of Physical Chemistry C, 121(25), 13593-13598.

https://doi.org/10.1021/acs.jpcc.7b05270

\section{General rights}

Copyright and moral rights for the publications made accessible in the public portal are retained by the authors and/or other copyright owners and it is a condition of accessing publications that users recognise and abide by the legal requirements associated with these rights.

- Users may download and print one copy of any publication from the public portal for the purpose of private study or research.

- You may not further distribute the material or use it for any profit-making activity or commercial gain

- You may freely distribute the URL identifying the publication in the public portal 


\title{
Two-dimensional MXenes as Catalysts for
}

\section{Electrochemical Hydrogen Evolution: A}

\section{Computational Screening Study}

\author{
Mohnish Pandey*,† and Kristian S. Thygesen ${ }^{\dagger, \ddagger}$ \\ CAMD, Department of Physics, Technical University of Denmark, DK - 2800 Kongens \\ Lyngby, Denmark, and Center for Nanostructured Graphene (CNG), Department of \\ Physics, Technical University of Denmark, DK - 2800 Kongens Lyngby, Denmark \\ E-mail: mohpa@fysik.dtu.dk \\ Phone: +45 4525 3204
}

\footnotetext{
*To whom correspondence should be addressed

${ }^{\dagger}$ CAMD, Department of Physics, Technical University of Denmark, DK - 2800 Kongens Lyngby, Denmark

${ }^{\ddagger}$ Center for Nanostructured Graphene (CNG), Department of Physics, Technical University of Denmark, DK - 2800 Kongens Lyngby, Denmark
} 


\begin{abstract}
We use density functional theory (DFT) calculations to explore different polymorphs of a new class of two-dimensional (2D) materials commonly known as MXenes which are primarily carbides and nitrides of transition metals. The stability of the $\mathrm{M}_{2} \mathrm{X}$, $\mathrm{M}_{3} \mathrm{X}_{2}$, and $\mathrm{M}_{4} \mathrm{X}_{3}$ polymorphs in their bare and functionalized forms is assessed via the calculated standard heat of formation. We find that most of the MXenes are metallic and we investigate their performance as electrocatalysts for the hydrogen evolution reaction (HER) using the free energy of hydrogen adsorption at equilibrium coverage as an activity descriptor. For a given type of metal, we find that the hydrogen adsorption energy can vary by up to $0.5 \mathrm{eV}$ depending on the number of metal layers in the structure, suggesting that the catalytic activity of MXenes can be tuned by controlling the layer thickness. Based on a combined stability and activity analysis of 72 different MXenes, we identify several new promising non-precious HER electrocatalysts.
\end{abstract}

\title{
Introduction
}

To limit the emission of green house gases from fossil fuels, the development of viable alternative energy resources that can replace the carbon based fuels is becoming increasingly important. In addition to chemical-free resources like photovoltaics, thermoeletrics and geothermal power, carbon-free chemical fuels are required for efficient energy storage and for production of materials and chemicals in general. Despite being the simplest of chemicals, hydrogen plays a key role in energy production (e.g. fuel cells) as well as in reduction processes in chemical synthesis. However, an economically viable and efficient process to generate hydrogen is still not fully developed. One of the main bottlenecks for efficient hydrogen production is the lack of a cheap and efficient catalyst. To date, platinum is the most widely used catalyst for the hydrogen evolution reaction (HER). While being very active and efficient with a low overpotential for the HER, the sustainable and large scale usage of platinum is hampered by its cost. It is therefore essential to find a cost-effective alternative 
to platinum.

One promising strategy for discovering new catalysts is computational screening by which the performance of a large number of potential catalyst materials is assessed by firstprinciples calculations before the most promising candidates are selected for experimental synthesis. This approach is often based on the concept of descriptors, i.e. simple quantities that can be easily calculated from first principles and which correlate directly with more complex properties that govern the performance of the catalyst. For example, the adsorption free energy of hydrogen is a descriptor for the HER activity while the heat of formation is a descriptor for the stability of the catalyst. ${ }^{1-5}$

Among numerous classes of materials which might replace platinum for the HER, some atomically thin two-dimensional (2D) materials have shown promising results. ${ }^{2-6} \mathrm{~A}$ unique feature of the $2 \mathrm{D}$ materials is that their extreme thinness makes it relatively easy to tune their properties, e.g. via mechanical strain, substrate effects, edge or defect engineering, ion intercalation/doping. ${ }^{3,7-12}$ Additionally, the rapid ramification of the family of $2 \mathrm{D}$ materials is continuously expanding this class of materials opening new opportunities for HER catalysis. $^{3,7-12}$

A newly discovered class of $2 \mathrm{D}$ materials comprising carbides and nitrides of transition metals, also known as 'MXenes', has shown promise for various energy applications. ${ }^{13-17}$ So far, the MXenes have mainly been explored for their prospective application in lithium/sodium ion batteries. Very recently, a joint experimental and theoretical study has also shown promises for the application of MXenes as HER catalysts. ${ }^{18}$ While the study by Seh et al. was focused on MXenes containing one metal layer in the structure, the present work considers a broader range of metals and explores how the thickness of the layers can be used to tune the catalytic properties of the MXenes. ${ }^{19}$ The possibility of controlling the thickness of the covalently bonded 2D layer is unique to the MXenes and increases the design flexibility compared to other well known 2D materials such as the transition metal dichalcogenides (TMDs). 
In this work, we perform a computational screening of the stability and catalytic activity for HER of MXenes of the type $\mathrm{M}_{2} \mathrm{X}, \mathrm{M}_{3} \mathrm{X}_{2}$, and $\mathrm{M}_{4} \mathrm{X}_{3}$ (M: transition metal; $\mathrm{X}$ : $\mathrm{N}, \mathrm{C}$ ) in both their bare and functionalized forms. The stability is assessed via the standard heat of formation $(\Delta \mathrm{H})$ whereas the catalytic activity towards HER is evaluated using free energy of hydrogen adsorption $\left(\Delta \mathrm{G}_{\mathrm{H}}\right)$ as a descriptor. ${ }^{4,20}$ We select transition metals guided by previous experimental works on MXenes which may be potentially synthesized; the list of the selected transition metals is shown in Figure 1. Additionally, we explore the role of using $\mathrm{O}, \mathrm{OH}$, and $\mathrm{F}$ as functional groups on the stability of MXenes. The rationale to use $\mathrm{O}$ and $\mathrm{OH}$ is the solvothermal synthesis of MXenes under acidic condition which will have $\mathrm{O} / \mathrm{OH}$ present to passivate the surface. ${ }^{15}$ Additionally, the passivation with $\mathrm{F}$ is due to the fact that the synthesis of MXenes is usually carried out by etching out certain elements from the structure using hydrofluoric acid (HF); therefore, it is likely that fluorine will be present

to functionalize the surface. ${ }^{15}$ We find that functionalization with $\mathrm{O}$ is thermodynamically preferred and therefore we limit the subsequent study of HER activity to O functionalized MXenes. Our calculations show that hydrogen adsorption on the MXenes depends sensitively on the number of metal layers suggesting that the layer thickness can be used as a means to control the catalytic activity. Based on the thermodynamic stability and free energy of hydrogen adsorption we propose a list of promising MXenes for further experimental investigation.

\section{Computational Methodology}

All the calculations were performed with the GPAW electronic structure code, which is based on the projector augmented wave (PAW) method. ${ }^{21}$ The lattice constants and heat of formation were calculated using the PBE exchange-correlation functional ${ }^{22}$ along with the fitted elemental reference phase (FERE) scheme to improve the description of the heat of formation. ${ }^{23,24}$ The calculation of adsorption energies was carried out using the RPBE 


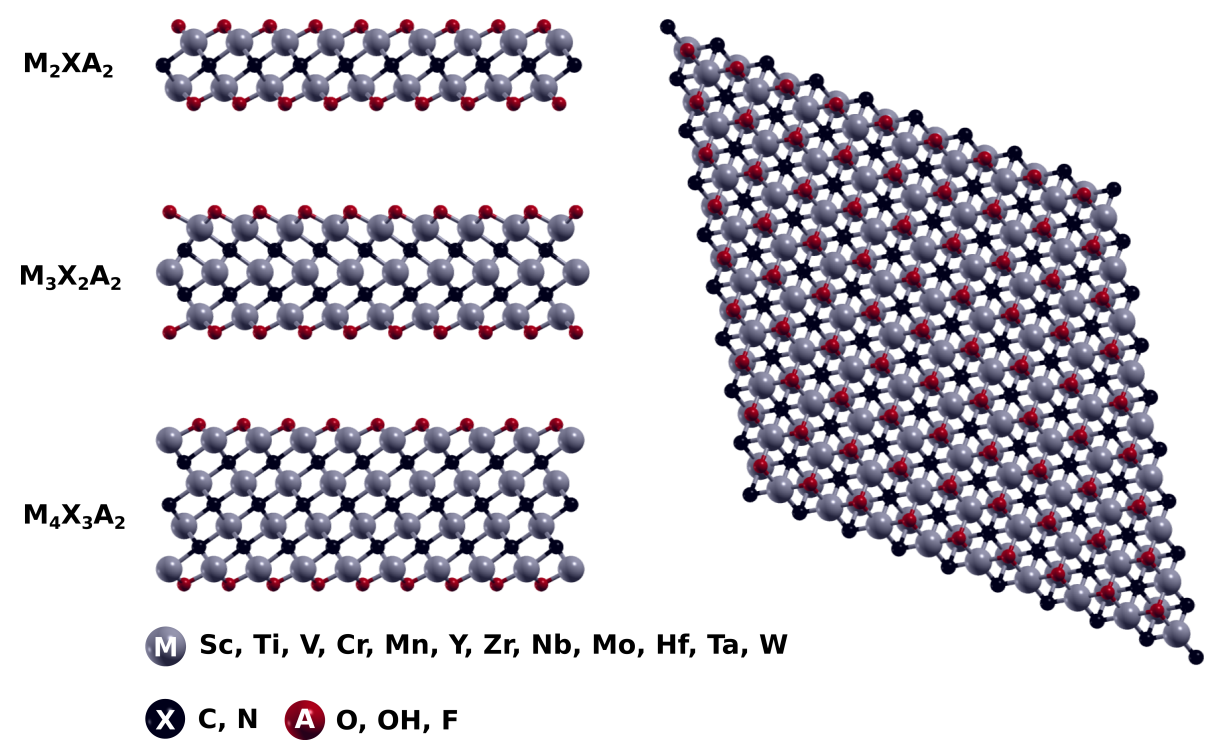

Figure 1: Ball and stick model of MXenes with different layer thickness. Left panel shows the side view of three functionalized MXenes $\mathrm{M}_{2} \mathrm{XA}_{2}, \mathrm{M}_{3} \mathrm{X}_{2} \mathrm{~A}_{2}$ and $\mathrm{M}_{4} \mathrm{X}_{3} \mathrm{~A}_{2}$ where $\mathrm{M}$ refers to the metal, $\mathrm{X}$ refers to carbon or nitrogen and A refers to the functional group present on the surface. The right panel shows the top view of MXenes.

functional which is which is known to improve adsorption energies on metal surfaces. ${ }^{25}$ Wave functions were expanded on a real space grid using a grid spacing of $0.16 \AA$. The Brillouin zone was sampled using a k-point mesh of $12 \times 12 \times 1$ with the Monkhorst-Pack sampling scheme $^{26}$ and a Fermi-Dirac smearing of $0.05 \mathrm{eV}$ was used to accelerate convergence. For all structural relaxations, the forces were converged to $0.03 \mathrm{eV} / \AA$ or below. Spin-polarization was taken into account in all calculations. For the calculation of the free energy of hydrogen adsorption we calculate the zero point energy of the adsorbed hydrogen on the surfaces for different coverages. The zero point energy and entropic corrections for the gaseous hydrogen was taken from Ref. 27 and 28, respectively. We ignored the entropic corrections for the adsorbed hydrogen on the surface. Taking all the corrections into account, we find that all the product state are shifted up in energy by $\sim 0.07 \mathrm{eV}$ since the corrections are very similar for all the compounds. 


\section{Results and Discussions}

Figure 1 shows the atomic structure of the investigated MXenes. The left panel shows the side view of the MXenes with varying number of metals layers in the structure and the right panel shows a top view (all structures have identical top view). Additionally, the list of transition metals constituting different MXenes is shown in the left panel of Figure 1. We first address the thermodynamic stability of the MXenes using the heat of formation, $\Delta \mathrm{H}$, as a descriptor. In addition to $\Delta \mathrm{H}$, other factors like the effect of the cell potential and separation into other competing phases, might also play a role for the stability, but we do not consider these in the present study. Figure 2 is a heat map showing the calculated standard heat of formation of the different MXenes. Left and right panels correspond to the carbide and nitride MXenes, respectively. The abscissa of the figures shows the metal atom in the MXene whereas the ordinate shows the type of the MXene including the name of the functional group used to passivate the surface. The heat map clearly shows that the carbides without functionalization are mostly unstable whereas the bare nitrides show better stability with most compounds having a negative $\Delta \mathrm{H}$. In general, functionalization with $\mathrm{O}, \mathrm{OH}$ or $\mathrm{F}$ enhances the stability of both carbides and nitrides. However, functionalization with F does not improve the stability significantly and is less favorable compared to functionalization with $\mathrm{O}$ and $\mathrm{OH}$ moities. An exception to these general trends occurs for the titanium-based MXenes, which show relatively high stability in both bare as well as F functionalized forms, yet still lower than the $\mathrm{O} / \mathrm{OH}$ functionalized forms.

As discussed above, the bare and F functionalized MXenes show rather poor stability and might not be stable under HER conditions. Additionally, functionalization with $\mathrm{OH}$ is indirectly connected to the primary step in HER. In particular, since for the $\mathrm{O}$ functionalized MXene, hydrogen binds to the oxygen atoms, the $\mathrm{OH}$ functionalized surface corresponds to the $\mathrm{O}$ functionalzied MXene under full $\mathrm{H}$ coverage. For these reasons, we focus in the following on HER at the $\mathrm{O}$ functionalized surfaces with different coverage of hydrogen. The first step involved in the HER according to both the Volmer-Tafel and Volmer-Heyrovsky 

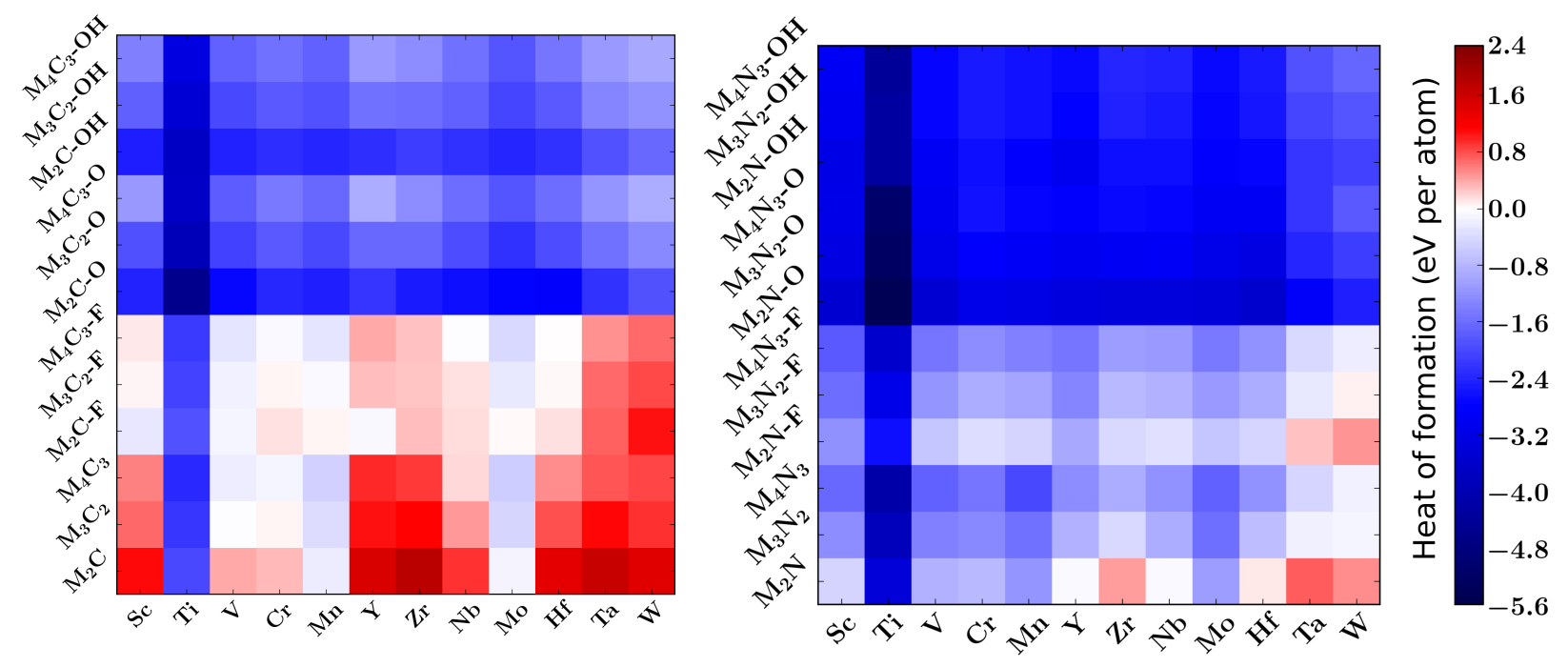

Figure 2: Standard heat of formation of bare and functionalized MXenes in eV/atom. The $\mathrm{M}$ in the heat map corresponds to the metal shown on the abscissa. The standard heat of formation is calculated with respect to the standard states of the elements where the energies of the standard state are corrected by the FERE method.

mechanisms is ${ }^{29-31}$

$$
\mathrm{H}^{+}+e^{-}+* \rightarrow \mathrm{H}^{*}
$$

In the expression above, $\mathrm{H}^{+}$and $\mathrm{H}^{*}$ denote the proton and adsorbed hydrogen, respectively. The subsequent step in the Volmer-Tafel mechanism is,

$$
2 \mathrm{H}^{*} \rightarrow \mathrm{H}_{2}+2 *
$$

whereas in the Volmer-Heyrovsky mechanism the second step is,

$$
\mathrm{H}^{*}+\mathrm{H}^{+}+e^{-} \rightarrow \mathrm{H}_{2}+*
$$

Assuming that $\mathrm{H}^{+}$and $\mathrm{H}_{2}$ are in equilibrium (i.e. the potential equals the reversible hydrogen electrode), the energy of the intermediate state $\mathrm{H}^{*}$ provides an effective thermodynamic barrier for the reaction in both the mechanisms. This suggests that in order to have a zero thermodynamic barrier for HER, the optimum free energy of adsorption, $\Delta \mathrm{G}_{\mathrm{H}}$, must 
be zero. Therefore, the equilibrium coverage of the surface under the reaction conditions, i.e. at the lowest potential at which the reaction runs, is the one that minimises the HER overpotential i.e. $\left|\Delta \mathrm{G}_{\mathrm{H}}\right|$.

Figure 3 shows the equilibrium coverage for all the MXenes explored. The $2 \times 2$ supercell used for the calculations results in four different coverages, $25 \%, 50 \%, 75 \%$, and $100 \%$. The figure clearly shows that a large fraction of the compounds explored operate under $25 \%$ coverage and only the Sc and Y MXenes adsorb hydrogen at full coverage. It is interesting to note that for several of the MXenes, the equilibrium coverage depends on the thickness. This behavior clearly indicates that the chemical properties of the MXenes can be engineered by controlling the layer thickness.

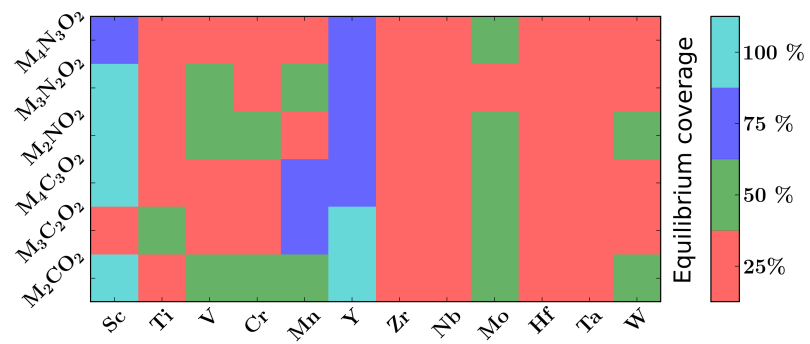

Figure 3: Heat map showing the equilibrium coverage for different MXenes under operating conditions, i.e. at the lowest potential where the HER runs. Under these conditions, the equilibrium coverage is defined as the coverage at which the differential free energy of hydrogen adsorption in closest to zero.

As pointed out above, it is essential to calculate the equilibrium coverage at a given potential in order to calculate the free energy of the reaction of interest. The $\mathrm{H}$ coverage in general is a function of potential. We use the equilibrium coverage, that is, the coverage relevant at the RHE potential (reversible hydrogen electrode). This approximation is justified for the most relevant cases where the $\Delta \mathrm{G}_{\mathrm{H}}$ is close to zero. Using the equilibrium coverage shown in Figure 3 the free energy for HER for different MXenes is calculated. Figure 4 shows negative of the overpotential plotted against $\Delta \mathrm{G}_{\mathrm{H}}$. Left and right panel correspond to the overpotential vs $\Delta \mathrm{G}_{\mathrm{H}}$ plot for the carbides and nitrides, respectively. Different symbols denote different layer thickness of the MXenes whereas different metals are identified by 
different colors. The figure clearly shows that the thickness has notable effect on $\Delta \mathrm{G}_{\mathrm{H}}$ in many cases. A large number of carbides and nitrides lie far in the leg of the volcano i.e. have $\Delta \mathrm{G}_{\mathrm{H}}$ significantly different from zero. This trend in $\Delta \mathrm{G}_{\mathrm{H}}$ leaves a large fraction of MXenes unsuitable to catalyze the HER. However, few MXenes lie near the top of the volcano which might be suitable candidates for HER catalysis.
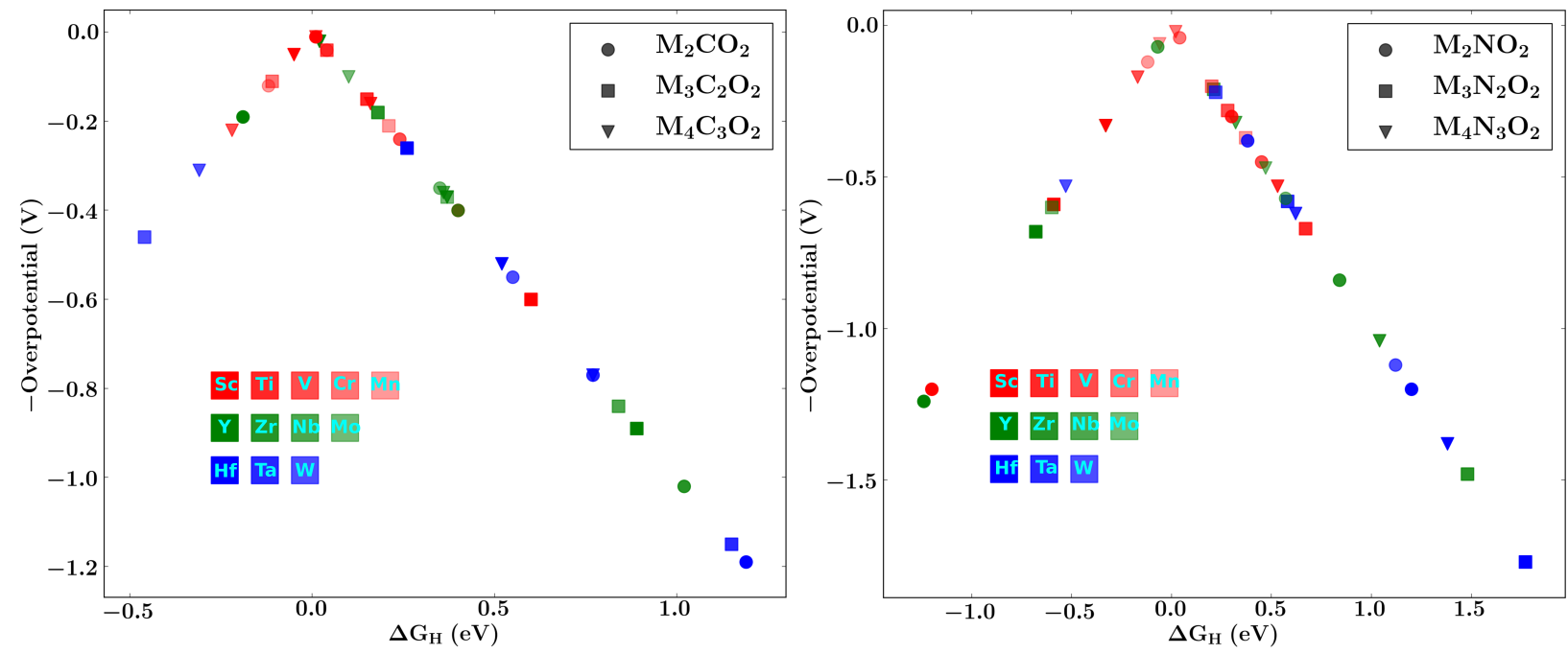

Figure 4: Negative of the overpotential of carbide and nitride MXenes (left and right panel, respectively) plotted versus the free energy of hydrogen adsorption $\left(\Delta G_{H}\right)$. The overpotential is defined as the absolute value of the difference of free energy of hydrogen adsorption and the optimum free energy for HER which is $0 \mathrm{eV}$.

Table 1 provides an overview of all the investigated MXenes together with the calculated heat of formation, free energy of hydrogen adsorption, and the electronic character of the MXene (metallic or semiconducting). For many compounds there is a striking variation in the hydrogen adsorption energy with layer thickness. Specifically, $\Delta G_{H}$ can vary by more than $0.5 \mathrm{eV}$ between MXenes containing one and three metal layers. Unfortunately, no clear dependence of adsorption energies on the layer thickness is observed. For example, in vandium carbides the adsorption energy decreases as the thickness is increased whereas the niobium and tantalum carbides which belong to the same group as vanadium do not manifest the similar trend. However, the optimum thickness for a particular material obtained with the calculations give the information of the thickness of the material needed to be synthesized 
thus reducing experimental effort.

In Ref. 18 the overpotential for HER on $\mathrm{Mo}_{2} \mathrm{CO}_{2}$ and $\mathrm{Ti}_{2} \mathrm{CO}_{2}$ was measured to be $\sim 0.35$ $\mathrm{V}$ and $\sim 0.8 \mathrm{~V}$, respectively. In comparison based on the calculated $\left|\Delta \mathrm{G}_{\mathrm{H}}\right|$, we obtain values of $0.35 \mathrm{~V}$ and $0.4 \mathrm{~V}$, respectively. Our result for $\mathrm{Mo}_{2} \mathrm{CO}_{2}$ agrees well with the measured overpotential of $0.35 \mathrm{~V}$, while it differs slightly from the calculated value in the same paper. In the case of $\mathrm{Ti}_{2} \mathrm{CO}_{2}$ the measured overpotential of $\sim 0.8 \mathrm{~V}$ is higher than our predicted value of $0.4 \mathrm{~V}$, which agrees with the DFT calculations in Ref. 18. We note that while our DFT calculations predict most of the MXenes to be metallic (including $\mathrm{Mo}_{2} \mathrm{CO}_{2}$ ), $\mathrm{Ti}_{2} \mathrm{CO}_{2}$ is found to be semiconducting with a PBE band gap of $0.4 \mathrm{eV}$. The non-metallic nature of $\mathrm{Ti}_{2} \mathrm{CO}_{2}$ suggest that the origin of the larger overpotential measured experimentally could be related to transport losses. Finally, we note that the scanning electron microscope (SEM) images of the MXenes samples in Ref. 18 show relatively large opaque particles which might indicate that the catalysis was not taking place on individual monolayers sheets as assumed in our study. This could be an alternative explanation for the observed disagreement between experiments and theory in the case of $\mathrm{Ti}_{2} \mathrm{CO}_{2}$.

In the discussion above we emphasized that the thermodynamic stability and the free energy of hydrogen adsorption on the MXenes play a crucial role in determining their suitability for HER. In Figure 5 we show the MXenes with negative heat of formation and $\left|\Delta \mathrm{G}_{\mathrm{H}}\right|$ $\leq 0.5 \mathrm{eV}$. The circled data points show compounds having $\left|\Delta \mathrm{G}_{\mathrm{H}}\right| \leq 0.1 \mathrm{eV}$. Among these "best candidates" we find several Cr compounds of different layer thicknesses making the chromium MXenes particularly interesting to explore further for HER. The best candidates are highlighted in Table 1.

\section{Conclusion}

In summary, we have explored a broad class of transition metal carbide and nitrides as electrocatalysts for the hydrogen evolution reaction (HER). Based on the calculated heat 
Table 1: The calculated heat of formation $(\Delta \mathrm{H}$ in $\mathrm{eV})$, free energy of hydrogen adsorption at equilibrium coverage for HER $\left(\Delta \mathrm{G}_{\mathrm{H}}\right.$ in $\left.\mathrm{eV}\right)$ and electronic character of the MXene (metallic or semiconducting). The best candidates which have $\left|\Delta \mathrm{G}_{\mathrm{H}}\right| \leq 0.1 \mathrm{eV}$ are written in bold.

\begin{tabular}{|c|c|c|c|c|c|c|c|}
\hline Carbides & $\Delta \mathrm{H}$ & $\Delta \mathrm{G}_{\mathrm{H}}$ & Metallic & Nitrides & $\Delta \mathrm{H}$ & $\Delta \mathrm{G}_{\mathrm{H}}$ & Metallic \\
\hline $\mathrm{Sc}_{2} \mathbf{C O}_{2}$ & -2.42 & 0.01 & yes & $\mathrm{Sc}_{2} \mathrm{NO}_{2}$ & -3.51 & -1.20 & yes \\
\hline $\mathrm{Sc}_{3} \mathrm{C}_{2} \mathrm{O}_{2}$ & -1.90 & 0.60 & yes & $\mathrm{Sc}_{3} \mathrm{~N}_{2} \mathrm{O}_{2}$ & -3.23 & -0.59 & yes \\
\hline $\mathrm{Sc}_{4} \mathrm{C}_{3} \mathrm{O}_{2}$ & -1.13 & -0.05 & yes & $\mathrm{Sc}_{4} \mathrm{~N}_{3} \mathrm{O}_{2}$ & -3.11 & -0.33 & yes \\
\hline $\mathrm{Ti}_{2} \mathrm{CO}_{2}$ & -4.57 & 0.40 & no & $\mathrm{Ti}_{2} \mathrm{NO}_{2}$ & -5.43 & 0.30 & yes \\
\hline $\mathrm{Ti}_{3} \mathrm{C}_{2} \mathrm{O}_{2}$ & -3.89 & 0.15 & yes & $\mathrm{Ti}_{3} \mathrm{~N}_{2} \mathrm{O}_{2}$ & -5.21 & 0.67 & no \\
\hline $\mathrm{Ti}_{4} \mathrm{C}_{3} \mathrm{O}_{2}$ & -3.65 & 0.16 & yes & $\mathrm{Ti}_{4} \mathrm{~N}_{3} \mathrm{O}_{2}$ & -5.10 & 0.53 & yes \\
\hline V2CO2 & -2.72 & 0.24 & yes & $\mathrm{V}_{2} \mathrm{NO}_{2}$ & -3.47 & 0.45 & yes \\
\hline $\mathbf{V} 3 \mathbf{C} 2 \mathrm{O} 2$ & -2.08 & 0.04 & yes & $\mathrm{V}_{3} \mathrm{~N}_{2} \mathrm{O}_{2}$ & -3.14 & 0.28 & yes \\
\hline V4C3O2 & -1.76 & -0.22 & yes & $\mathrm{V}_{4} \mathrm{~N}_{3} \mathrm{O}_{2}$ & -2.98 & -0.17 & yes \\
\hline $\mathrm{Cr}_{2} \mathrm{CO}_{2}$ & -2.37 & 0.04 & yes & $\mathrm{Cr}_{2} \mathrm{NO}_{2}$ & -3.11 & 0.04 & yes \\
\hline $\mathrm{Cr}_{3} \mathrm{C}_{2} \mathrm{O}_{2}$ & -1.80 & -0.11 & yes & $\mathrm{Cr}_{3} \mathrm{~N}_{2} \mathrm{O}_{2}$ & -2.83 & 0.20 & yes \\
\hline $\mathrm{Cr}_{4} \mathrm{C}_{3} \mathrm{O}_{2}$ & -1.46 & 0.01 & yes & $\mathrm{Cr}_{4} \mathbf{N}_{3} \mathrm{O}_{2}$ & -2.61 & 0.02 & yes \\
\hline $\mathrm{Mn}_{2} \mathrm{CO}_{2}$ & -2.49 & -0.12 & yes & $\mathrm{Mn}_{2} \mathrm{NO}_{2}$ & -3.17 & -0.12 & yes \\
\hline $\mathrm{Mn}_{3} \mathrm{C}_{2} \mathrm{O}_{2}$ & -1.99 & 0.21 & yes & $\mathrm{Mn}_{3} \mathrm{~N}_{2} \mathrm{O}_{2}$ & -2.89 & 0.37 & yes \\
\hline $\mathrm{Mn}_{4} \mathrm{C}_{3} \mathrm{O}_{2}$ & -1.64 & 0.01 & yes & $\mathrm{Mn}_{4} \mathrm{~N}_{3} \mathrm{O}_{2}$ & -2.72 & -0.06 & yes \\
\hline $\mathrm{Y}_{2} \mathrm{CO}_{2}$ & -2.21 & -0.19 & yes & $\mathrm{Y}_{2} \mathrm{NO}_{2}$ & -3.31 & -1.24 & yes \\
\hline $\mathrm{Y}_{3} \mathrm{C}_{2} \mathrm{O}_{2}$ & -1.64 & 0.89 & yes & $\mathrm{Y}_{3} \mathrm{~N}_{2} \mathrm{O}_{2}$ & -2.98 & -0.68 & yes \\
\hline $\mathbf{Y}_{4} \mathbf{C}_{3} \mathbf{O}_{2}$ & -0.88 & 0.02 & yes & $\mathrm{Y}_{4} \mathrm{~N}_{3} \mathrm{O}_{2}$ & -2.82 & -0.33 & yes \\
\hline $\mathrm{Zr}_{2} \mathrm{CO}_{2}$ & -2.51 & 1.02 & no & $\mathrm{Zr}_{2} \mathrm{NO}_{2}$ & -3.33 & 0.84 & yes \\
\hline $\mathrm{Zr}_{3} \mathrm{C}_{2} \mathrm{O}_{2}$ & -1.63 & 0.18 & no & $\mathrm{Zr}_{3} \mathrm{~N}_{2} \mathrm{O}_{2}$ & -2.96 & 1.48 & no \\
\hline $\mathrm{Zr}_{4} \mathrm{C}_{3} \mathrm{O}_{2}$ & -1.26 & 0.37 & yes & $\mathrm{Zr}_{4} \mathrm{~N}_{3} \mathrm{O}_{2}$ & -2.70 & 1.04 & yes \\
\hline $\mathrm{Nb}_{2} \mathrm{CO}_{2}$ & -2.65 & 0.40 & yes & $\mathrm{Nb}_{2} \mathrm{NO}_{2}$ & -3.33 & -0.07 & yes \\
\hline $\mathrm{Nb}_{3} \mathrm{C}_{2} \mathrm{O}_{2}$ & -1.95 & 0.84 & yes & $\mathrm{Nb}_{3} \mathrm{~N}_{2} \mathrm{O}_{2}$ & -2.90 & 0.21 & yes \\
\hline $\mathrm{Nb}_{4} \mathrm{C}_{3} \mathrm{O}_{2}$ & -1.60 & 0.36 & yes & $\mathrm{Nb}_{4} \mathrm{~N}_{3} \mathrm{O}_{2}$ & -2.74 & 0.32 & yes \\
\hline $\mathrm{Mo}_{2} \mathrm{CO}_{2}$ & -2.77 & 0.35 & yes & $\mathrm{Mo}_{2} \mathrm{NO}_{2}$ & -3.41 & 0.57 & yes \\
\hline $\mathrm{Mo}_{3} \mathrm{C}_{2} \mathrm{O}_{2}$ & -2.24 & 0.37 & yes & $\mathrm{Mo}_{3} \mathrm{~N}_{2} \mathrm{O}_{2}$ & -3.14 & -0.60 & yes \\
\hline $\mathrm{Mo}_{4} \mathrm{C}_{3} \mathrm{O}_{2}$ & -1.87 & 0.10 & yes & $\mathrm{Mo}_{4} \mathrm{~N}_{3} \mathrm{O}_{2}$ & -2.95 & 0.47 & yes \\
\hline $\mathrm{Hf}_{2} \mathrm{CO}_{2}$ & -2.81 & 1.19 & no & $\mathrm{Hf}_{2} \mathrm{NO}_{2}$ & -3.58 & 1.20 & yes \\
\hline $\mathrm{Hf}_{3} \mathrm{C}_{2} \mathrm{O}_{2}$ & -1.94 & 0.26 & no & $\mathrm{Hf}_{3} \mathrm{~N}_{2} \mathrm{O}_{2}$ & -3.22 & 1.77 & no \\
\hline $\mathrm{Hf}_{4} \mathrm{C}_{3} \mathrm{O}_{2}$ & -1.60 & 0.52 & yes & $\mathrm{Hf}_{4} \mathrm{~N}_{3} \mathrm{O}_{2}$ & -2.95 & 1.38 & yes \\
\hline $\mathrm{Ta}_{2} \mathrm{CO}_{2}$ & -2.27 & 0.77 & yes & $\mathrm{Ta}_{2} \mathrm{NO}_{2}$ & -2.87 & 0.38 & yes \\
\hline $\mathrm{Ta}_{3} \mathrm{C}_{2} \mathrm{O}_{2}$ & -1.53 & 1.15 & yes & $\mathrm{Ta}_{3} \mathrm{~N}_{2} \mathrm{O}_{2}$ & -2.38 & 0.58 & yes \\
\hline $\mathrm{Ta}_{4} \mathrm{C}_{3} \mathrm{O}_{2}$ & -1.18 & 0.77 & yes & $\mathrm{Ta}_{4} \mathrm{~N}_{3} \mathrm{O}_{2}$ & -2.19 & 0.62 & yes \\
\hline $\mathrm{W}_{2} \mathrm{CO}_{2}$ & -1.89 & 0.55 & yes & $\mathrm{W}_{2} \mathrm{NO}_{2}$ & -2.47 & 1.12 & yes \\
\hline $\mathrm{W}_{3} \mathrm{C}_{2} \mathrm{O}_{2}$ & -1.29 & -0.46 & yes & $\mathrm{W}_{3} \mathrm{~N}_{2} \mathrm{O}_{2}$ & -2.12 & 0.22 & yes \\
\hline $\mathrm{W}_{4} \mathrm{C}_{3} \mathrm{O}_{2}$ & -0.90 & -0.31 & yes & $\mathrm{W}_{4} \mathrm{~N}_{3} \mathrm{O}_{2}$ & -1.81 & -0.53 & yes \\
\hline
\end{tabular}




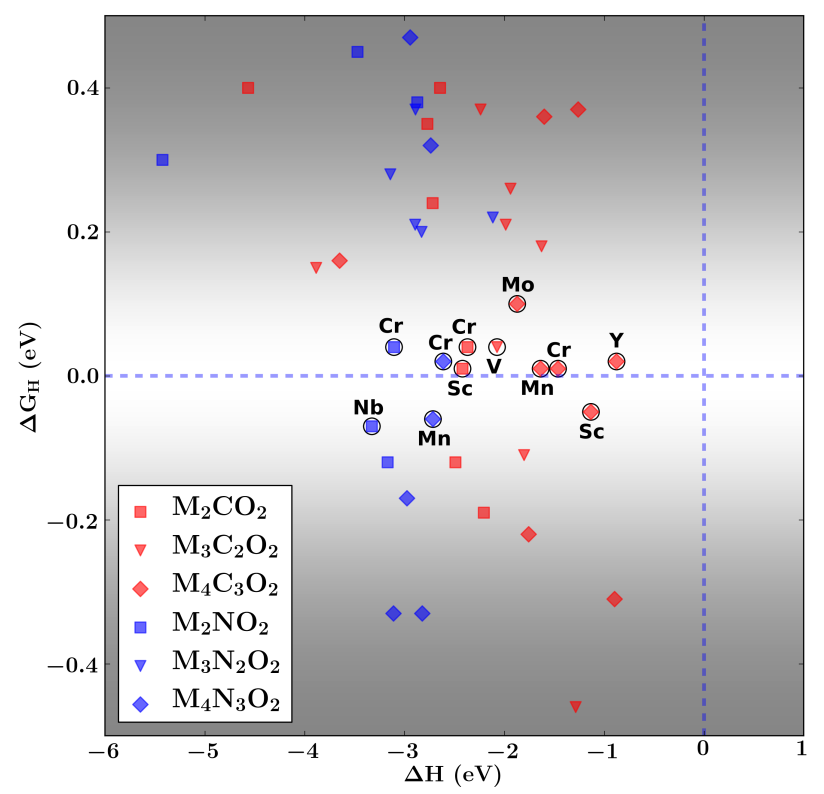

Figure 5: $\Delta \mathrm{H}$ versus $\Delta \mathrm{G}_{\mathrm{H}}$ plot for MXenes which have $\left|\Delta \mathrm{G}_{\mathrm{H}}\right| \leq 0.5 \mathrm{eV}$. The circled data points denote the compounds which have $\left|\Delta \mathrm{G}_{\mathrm{H}}\right| \leq 0.1 \mathrm{eV}$ thus have have probability to act as good HER cathode material. The name of the metal atom constituting the MXenes is written next to the data points.

of formation we find that most of the MXenes are unstable in absence of functionalizing agents passivating the surfaces. However, functionalization of the MXenes with species which are present during their synthesis enhances the thermodynamic stability. We find that functionalization with oxygen is favored in most cases, and the oxygen passivated MXenes were explored for the HER at different coverages of hydrogen. Using free energy of hydrogen adsorption as a primary descriptor we found that the thickness of the covalently bonded MXene monolayers play an important role and can be used to tune the activity of MXenes for the HER. Our screening procedure identified a number of promising MXenes with good stability properties and predicted high activity for HER.

\section{Acknowledgments}

The Center for Nanostructured Graphene is sponsored by the Danish National Research Foundation, Project DNRF103. This work was partly supported by a research grant (9455) 
from VILLUM FONDEN. Authors acknowledge Jakob Kibsgaard from DTU Physics for helpful discussions. 


\section{References}

(1) Norskov, J. K.; Bligaard, T.; Rossmeisl, J.; Christensen, C. H. Towards the Computational Design of Solid Catalysts. Nat. Chem. 2009, 1, 37-46.

(2) Voiry, D.; Salehi, M.; Silva, R.; Fujita, T.; Chen, M.; Asefa, T.; Shenoy, V. B.; Eda, G.; Chhowalla, M. Conducting $\mathrm{MoS}_{2}$ Nanosheets as Catalysts for Hydrogen Evolution Reaction. Nano Lett. 2013, 13, 6222-6227.

(3) Wang, H.; Lu, Z.; Kong, D.; Sun, J.; Hymel, T. M.; Cui, Y. Electrochemical Tuning of $\mathrm{MoS}_{2}$ Nanoparticles on Three-dimensional Substrate for Efficient Hydrogen Evolution. ACS Nano 2014, 8, 4940-4947.

(4) Pandey, M.; Vojvodic, A.; Thygesen, K. S.; Jacobsen, K. W. Two-Dimensional Metal Dichalcogenides and Oxides for Hydrogen Evolution: A Computational Screening Approach. J. Phys. Chem. Lett. 2015, 6, 1577-1585.

(5) Voiry, D.; Yamaguchi, H.; Li, J.; Silva, R.; Alves, D. C. B.; Fujita, T.; Chen, M.; Asefa, T.; Shenoy, V. B.; Eda, G.; Chhowalla, M. Enhanced Catalytic Activity in Strained Chemically Exfoliated $\mathrm{WS}_{2}$ Nanosheets for Hydrogen Evolution. Nat. Mater. 2013, 12, 850-855.

(6) Hinnemann, B.; Moses, P. G.; Bonde, J.; Jørgensen, K. P.; Nielsen, J. H.; Horsch, S.; Chorkendorff, I.; Nørskov, J. K. J. Am. Chem. Soc. 2005, 127, 5308-5309.

(7) Kan, M.; Wang, J. Y.; Li, X. W.; Zhang, S. H.; Li, Y. W.; Kawazoe, Y.; Sun, Q.; Jena, P. Structures and Phase Transition of a $\mathrm{MoS}_{2}$ Monolayer. J. Phys. Chem. C 2014, 118, 1515-1522.

(8) Pandey, M.; Bothra, P.; Pati, S. K. Phase Transition of $\mathrm{MoS}_{2}$ Bilayer Structures. J. Phys. Chem. C 2016, 120, 3776-3780. 
(9) Pandey, M.; Rasmussen, F. A.; Kuhar, K.; Olsen, T.; Jacobsen, K. W.; Thygesen, K. S. Defect-Tolerant Monolayer Transition Metal Dichalcogenides. Nano Lett. 2016, 16, $2234-2239$.

(10) Li, H.; Tsai, C.; Koh, A. L.; Cai, L.; Contryman, A. W.; Fragapane, A. H.; Zhao, J.; Han, H. S.; Manoharan, H. C.; A.-Pedersen, F.; Nørskov, J. K.; Zheng, X. Activating and Optimizing $\mathrm{MoS}_{2}$ Basal Planes for Hydrogen Evolution Through the Formation of Strained Sulphur Vacancies. Nat. Mater. 2016, 15, 48-53.

(11) Pandey, M.; Jacobsen, K. W.; Thygesen, K. S. Atomically Thin Ordered Alloys of Transition Metal Dichalcogenides: Stability and Band Structures. J. Phys. Chem. C 2016, 120, 23024-23029.

(12) Pandey, M.; Jacobsen, K. W.; Thygesen, K. S. Band Gap Tuning and Defect Tolerance of Atomically Thin Two-Dimensional Organic-Inorganic Halide Perovskites. J. Phys. Chem. Lett. 2016, 7, 4346-4352.

(13) Naguib, M.; Come, J.; Dyatkin, B.; Presser, V.; Taberna, P.-L.; Simon, P.; Barsoum, M. W.; Gogotsi, Y. MXene: A Promising Transition Metal Carbide Anode for Lithium-Ion Batteries. Electrochem. Commun. 2012, 16, 61-64.

(14) Lukatskaya, M. R.; Mashtalir, O.; Ren, C. E.; Dall'Agnese, Y.; Rozier, P.; Taberna, P. L.; Naguib, M.; Simon, P.; Barsoum, M. W.; Gogotsi, Y. Cation Intercalation and High Volumetric Capacitance of Two-Dimensional Titanium Carbide. Science 2013, 341, 1502-1505.

(15) Naguib, M.; Kurtoglu, M.; Presser, V.; Lu, J.; Niu, J.; Heon, M.; Hultman, L.; Gogotsi, Y.; Barsoum, M. W. Two-Dimensional Nanocrystals Produced by Exfoliation of $\mathrm{Ti}_{3} \mathrm{AlC}_{2}$. Adv. Mater. 2011, 23, 4248-4253.

(16) Naguib, M.; Mashtalir, O.; Carle, J.; Presser, V.; Lu, J.; Hultman, L.; Gogotsi, Y.; 
Barsoum, M. W. Two-Dimensional Transition Metal Carbides. ACS Nano 2012, 6, 1322-1331.

(17) Naguib, M.; Mochalin, V. N.; Barsoum, M. W.; Gogotsi, Y. 25th Anniversary Article: MXenes: A New Family of Two-Dimensional Materials. Adv. Mater. 2014, 26, 9921005.

(18) Seh, Z. W.; Fredrickson, K. D.; Anasori, B.; Kibsgaard, J.; Strickler, A. L.; Lukatskaya, M. R.; Gogotsi, Y.; Jaramillo, T. F.; Vojvodic, A. Two-Dimensional Molybdenum Carbide (MXene) as an Efficient Electrocatalyst for Hydrogen Evolution. ACS Ener. Lett. 2016, 1, 589-594.

(19) Anasori, B.; Xie, Y.; Beidaghi, M.; Lu, J.; Hosler, B. C.; Hultman, L.; Kent, P. R. C.; Gogotsi, Y.; Barsoum, M. W. Two-Dimensional, Ordered, Double Transition Metals Carbides (MXenes). ACS Nano 2015, 9, 9507-9516.

(20) Greeley, J.; Jaramillo, T. F.; Bonde, J. L.; Chorkendorff, I.; Nørskov, J. K. Computational High-Throughput Screening of Electrocatalytic Materials for Hydrogen Evolution. Nat. Mater. 2006, 5, 909-913.

(21) Enkovaara, J.; Rostgaard, C.; Mortensen, J. J.; Chen, J.; Dułak, M.; Ferrighi, L.; Gavnholt, J.; Glinsvad, C.; Haikola, V.; Hansen, H. A.; et al., Electronic Structure Calculations with GPAW: a Real-space Implementation of the Projector Augmentedwave Method. J. Phys.: Condens. Matter 2010, 22, 253202.

(22) Perdew, J. P.; Burke, K.; Ernzerhof, M. Generalized Gradient Approximation Made Simple. Phys. Rev. Lett. 1996, 77, 3865.

(23) Stevanović, V.; Lany, S.; Zhang, X.; Zunger, A. Correcting Density Functional Theory for Accurate Predictions of Compound Enthalpies of Formation: Fitted Elementalphase Reference Energies. Phys. Rev. B 2012, 85, 115104. 
(24) Pandey, M.; Jacobsen, K. W. Heats of Formation of Solids with Error Estimation: The mBEEF Functional with and without Fitted Reference Energies. Phys. Rev. B 2015, 91,235201 .

(25) Hammer, B.; Hansen, L. B.; Nørskov, J. K. Improved Adsorption Energetics Within Density-functional Theory Using Revised Perdew-Burke-Ernzerhof Functionals. Phys. Rev. B 1999, 59, 7413-7421.

(26) Monkhorst, H. J.; Pack, J. D. Special Points for Brillouin-zone Integrations. Phys. Rev. $B$ 1976, 13, 12 .

(27) Irikura, K. K. Experimental Vibrational Zero-Point Energies: Diatomic Molecules. J. Phys. Chem. Ref. Data 2007, 36, 389.

(28) Linstrom, P. J.; Mallard, W. NIST Chemistry WebBook, NIST Standard Reference Database 69; National Institute of Standards and Technology, Gaithersburg MD, 20899, 1998.

(29) Trasatti, S. Work Function, Electronegativity, and Electrochemical Behaviour of Metals: III. Electrolytic Hydrogen Evolution in Acid Solutions. J. Electroanal. Chem. 1972, 39, 163.

(30) Bockris, J. O.; Reddy, A. K. N.; Gamboa-Aldeco, M. Modern Electrochemistry 2A 2nd ed.; Kluwer Academic/Plenum Publishers: New York, 1998; pp 1167-1169.

(31) Tang, Q.; Jiang, D.-e. Mechanism of Hydrogen Evolution Reaction on 1T-MoS2 from First Principles. ACS Catal. 2016, 6, 4953-4961. 


\section{TOC Graphic}

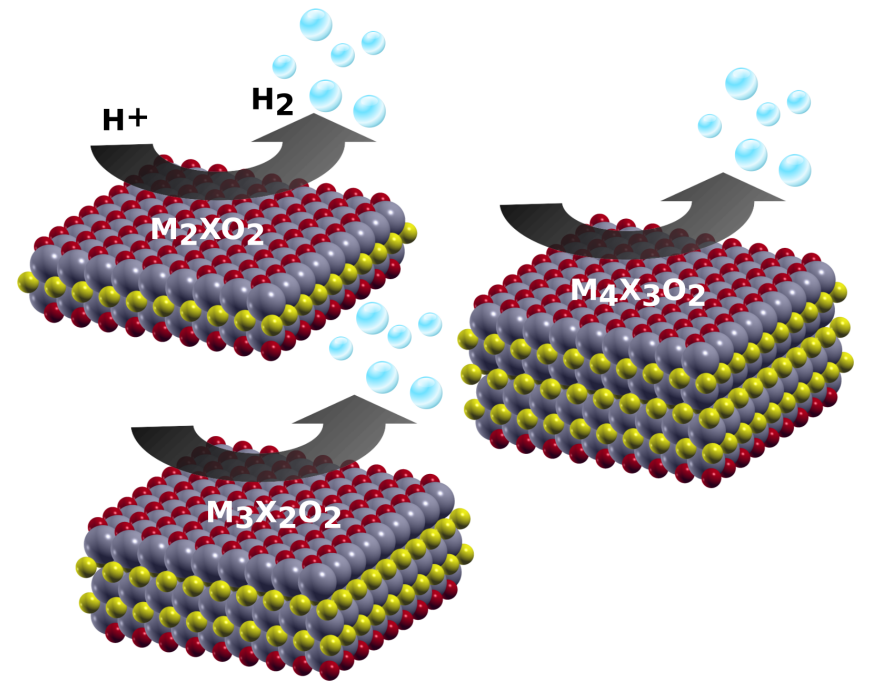

